\title{
Modulation of nociceptive-like behavior in zebrafish (Danio rerio) by environmental stressors
}

\author{
Caio Maximino \\ Universidade Federal do Pará, Belém, PA, Brazil
}

\begin{abstract}
Zebrafish have been demonstrated to react consistently to noxious chemical stimuli and present reliable phenotypes of stress, fear, and anxiety. In this article, we describe the modulation of nociceptive-like responses of zebrafish to fear-, stress-, and anxiety-eliciting situations. Animals were exposed to an alarm substance, confinement stress, or a novel environment before being injected with $1 \%$ acetic acid in the tail. The alarm substance and confinement stress reduced the display of erratic movements and tail-beating behavior elicited by acetic acid. The novelty of the environment, in contrast, increased the frequency of tail-beating behavior. The results suggest that descending modulatory control of nociception exists in zebrafish, with apparent fear- and stress-induced analgesia and anxiety-induced hyperalgesia. Keywords: nociception, defensive behavior, fear, anxiety, stress, zebrafish.
\end{abstract}

Received 8 November 2010; received in revised form 4 March 2011; accepted 4 March 2011. Available on line 15 June 2011

\section{Introduction}

Nociception has been proposed to be a widespread function in vertebrates, with evidence of its existence in taxa as basal as teleost fish (Dunlop \& Laming, 2005; Sneddon, Braithwaite, \& Gentle, 2003b). Evidence shows that not only fish have peripheral nociceptors (Sneddon, Braithwaite, \& Gentle, 2003a; Sneddon, 2003b; Sneddon \& Gentle, 2002), but also present centrally mediated responses to nociceptive stimulation. These animals exhibit behavioral responses to peripheral nociceptive stimulation (Nordgreen et al., 2009; Prober et al., 2008; Reilly, Quinn, Cossins, \& Sneddon, 2008a; Sneddon, 2003a, b), and these responses are processed centrally. For example, electrical (Dunlop \& Laming, 2005; Nordgreen, Horsberg, Ranheim, \& Chen, 2007) and gene-expression (Reilly, Quinn, Cossins, \& Sneddon, 2008b) responses to nociceptive stimuli were recorded in the tectum and telencephalon of teleost fish. Zebrafish have peripheral and central opioid receptors, which are pharmacologically analogous to those found in vertebrates (Barrallo, Gonzalez-Sarmiento, Alvar, \& Rodríguez, 2000; González-Nuñez, Barallo, Traynor, \& Rodríguez, 2006; González-Nuñez, GonzalezSarmiento, \& Rodríguez, 2003a, b, c; González-Nuñez

Caio Maximino, Laboratório de Neuroendocrinologia, Instituto de Ciências Biológicas, UFPa, Brazil; Zebrafish Neuroscience Research Consortium, Tulane University, U.S.A. Correspondence regarding this article should be directed to: Laboratory of Neuroendocrinology, Institute of Biological Sciences, UFPa, Augusto Corrêa street, 01, 66075-110-Belém/PA,Brazil.E-mail:caio@ufpa.br
\& Rodriguez, 2009; Rodríguez Barrallo, Garcia-Malvar, McFayden, Gonzalez-Sarmiento, \& Traynor, 2000), and a paleospinothalamic pathway (Becker, Wullimann, Becker, Bernhardt, \& Schachner, 1997) that, in mammals, is thought to conduct nociceptive information to sensory and limbic areas of the central nervous system (Liu, 1986). In common carps (Cyprinus carpio, a closely related cyprinid), an acetic acid injection in the lips produced "rocking" behavior (Reilly et al., 2008a) and up- or downregulated the genes that code for kainate glutamatergic and cannabinoid $\mathrm{CB}_{1}$ receptors and brain-derived neurotrophic factor (Reilly et al., 2008b). This evidence indicates the existence of ascending pathways that conduct nociceptive information to the brain of cyprinid fish.

The motivational component of nociception is thought to be bidirectional. Pain is a powerful motivator for recuperative behavior but is also inhibited by environmental stressors that trigger defensive behavior (Amit \& Galina, 1986; Bolles \& Fanselow, 1980). This latter phenomenon, usually termed stress-induced analgesia or fear-induced analgesia, is thought to be adaptive because the allocation of attentive resources to defensive strategies at the detriment of nociception increases the chances of successful antipredatory behavior (Amit \& Galina, 1986; Bolles \& Fanselow, 1980). Thus, threatening situations increase the nociceptive threshold, enabling the animal to execute proper defensive behavior to remove itself from the threat. Stress-induced analgesia is mediated by many different neurochemical systems, including opioid, $\gamma$-aminobutyric acid, glutamate, cannabinoid, serotonin, 
and norepinephrine systems, and stress hormones (Butler \& Finn, 2009). Each of these systems is highly conserved in the central nervous system of zebrafish (Alderman \& Bernier, 2007; Ampatzis \& Dermon, 2010; Ampatzis, Kentouri, \& Dermon, 2008; Chandrasekar, Lauter, \& Hauptmann, 2007; González-Nuñez \& Rodriguez, 2009; Kim, Nam, Yoo, \& Lee, 2004; Lam, Rastegar, \& Strähle, 2006; Lillesaar, Stigloher, Tannhäuser, Wullimann, \& Bally-Cuif, 2009). The degree of uncertainty of threat appears to modulate this response. In humans, experimental situations that are thought to involve fear (proximal threat) increase the nociceptive threshold, whereas situations that produce anxiety (potential threat) decrease it (Rhudy \& Meagher, 2000). Results in animal models are contradictory, with some studies showing no effect, hypoalgesia, or hyperalgesia after anxiogenic situations (Butler \& Finn, 2009). Fear and anxiety are now understood as different but interrelated processes, with fear representing the behavioral and neurovegetative responses to proximal threat, and anxiety representing the adjustments to a threat that is merely potential (Blanchard \& Blanchard, 2008). Fear and anxiety responses are organized at different levels in a putative rostro-caudal hierarchical circuitry for defense reactions (McNaughton \& Corr, 2004); therefore, we predict that direct exposure to threatening stimuli should induce high levels of fear and arousal and inhibit pain, whereas exposure to diffuse or potentially threatening stimuli (e.g., novelty) induce a state of anxiety and enhance pain (Rhudy \& Meagher, 2000). Aside from anxiety and fear, stressful stimuli that do not produce fear but induce neuroendocrine responses (e.g., restraint stress, social isolation, and forced swimming) can induce analgesia (Bodnar, Glusman, Brutus, Spiaggia, \& Kelly, 1979; Bodnar, Kelly, Spiaggia, Ehrenberg, \& Glusman, 1978; Bodnar, Merrigan, \& Sperber, 1983; Costa, Smeraldi, Tassorelli, Greco, \& Nappi, 2005; Puglisi-Allegra \& Oliverio, 1983), an effect that is mediated by hypothalamicpituitary-adrenal axis hormones (Butler \& Finn, 2009).

In fish, the only extant work that has studied the role of defensive behavior in the modulation of nociception is that of Sneddon and colleagues regarding the novel object test (Sneddon et al., 2003b). The presentation of a novel object in the tank produces signs of neophobia, including avoidance of the novel object and increased respiratory frequency. The frequency of rubbing behaviors, but not rocking, after acid injection to the lips of rainbow trout decreased after presentation of a novel object (Sneddon et al., 2003b). No effect was observed when the animals were habituated to the object. However, the results are difficult to interpret because acid-injected animals spent more time closer to the novel object than controls, suggesting that these animals were not avoiding it. Although the authors argue that this was attributable to noxious stimulation "drawing" more attention than fear, some evidence indicates that fear is not the only motivation in novel object exploration (Powell, Geyer, Gallagher, \& Paulus, 2004). Indeed, fish from the control group showed a biphasic temporal distribution of novel object avoidance, suggesting approach-avoidance conflict.

The novel object test may not be the best approach to elicit fear in fish, but an alarm substance released after damage to epidermal club cells of conspecifics is capable of doing so in Ostariophysi (Pfeiffer, 1977; von Frisch, 1938, 1941). In that regard, alarm substance-induced reactions, such as increased bottom-dwelling, erratic swimming, and freezing, closely parallel those produced by visual contacts with predators or predator models in zebrafish (Gerlai, 2010). This species is a well-established laboratory model whose genome is almost completely mapped and that shows robust behavioral phenotypes of fear, anxiety, and stress (Barcellos et al., 2007; Mathur \& Guo, 2010; Maximino et al., 2010; Norton \& Bally-Cuif, 2010). It also shows marked nociceptive-like responses to chemical noxious irritants (Prober et al., 2008; Reilly et al., 2008a) and a relatively well-conserved opioidergic system (Barrallo et al., 2000; González-Nuñez et al., 2006; González-Nuñez et al., 2003a, b, c; GonzálezNuñez, \& Rodriguez, 2009; Rodríguez et al., 2000). This species, therefore, is ideal for the study of the modulation of nociception by fear- and anxiety-eliciting environmental stressors in teleost fish. In this work, we analyzed the effects of alarm substance-induced fear, novelty-induced anxiety, and confinement stress in the nociceptive responses of zebrafish to acetic acid.

\section{Methods}

\section{Animals and housing}

One hundred thirty-two adult wildtype zebrafish (shortfin phenotype) were kept in collective 40 liter tanks ( $n=20$ fish per tank) for 2 weeks before the experiments began. The water was reconstituted and buffered to $\mathrm{pH} 7.0$ (Mydor Target 7.0 buffer), and the tanks had constant filtering, temperature control $(27 \pm$ $\left.2^{\circ} \mathrm{C}\right)$, illumination $(14 \mathrm{~h} / 10 \mathrm{~h}$, lights on at 7:00 AM), and feeding (Oscar Gold pellet ration). The animals were used only in the present experiment. Rearing and welfare conditions were in accordance with the standards set by ASAB/ABS (2006) and Colégio de Experimentação Animal - COBEA/Brazil (Andersen et al., 2008) and were approved by UFPA's Ethics Committee.

\section{Experiment 1: Effects of alarm substance exposure on nociceptive-like responses in zebrafish}

Two groups of animals ( $n=16$ per group) were transported daily to the observation apparatus $(10 \mathrm{~cm}$ length $\times 10 \mathrm{~cm}$ width $\times 20 \mathrm{~cm}$ height Plexiglas tank containing water from the home tank) and left there, individually, to explore the tank for $10 \mathrm{~min}$. Afterward, they were returned to their home tank. On the sixth day, 
16 animals were transferred to a 2 liter beaker containing $3.5 \mathrm{ml} / 1$ skin extract (alarm substance) made as proposed by Waldman (1982). Briefly, excess water was removed from the skin of the donor zebrafish with a paper towel. The animal was then quickly sacrificed by immersion in a lethal dose of MS 222. Fifteen shallow cuts were made on each side of the trunk of 10 donor fish, and the cuts were washed with Milli-Q water. Care was taken not to contaminate the solution with blood. A total of 100 $\mathrm{ml}$ of alarm substance solution was collected, and the aliquots were diluted to a $50 \%$ concentration. A second group of animals $(n=16)$ was also transferred to a 2 liter beaker that did not contain alarm substance.

After 5 min exposure to either regular water or alarm substance-spiked water, these animals were removed from the exposure beaker and quickly injected with either $5 \mu \mathrm{l}$ of Cortland's salt solution (Perry, Davie, Daxboeck, Ellis, \& Smith, 1984; 124.1 mM NaCl, 5.1 mM KCl, 2.9 $\mathrm{Na}_{2} \mathrm{HPO}_{4}, 1.9 \mathrm{mM} \mathrm{MgSO} \cdot 7 \mathrm{H}_{2} \mathrm{O}, 1.4 \mathrm{mM} \mathrm{CaCl} \cdot 2 \mathrm{H}_{2} \mathrm{O}$, $11.9 \mathrm{mM} \mathrm{NaHCO}_{3}$, and 1,000 USP units of heparin) or Cortland's solution with $1 \%$ acetic acid in the tail in a region near the adipose fin. The final composition of the groups ( $n=8$ per group) was the following: $(i)$ pure water + Cortland's, (ii) pure water + acetic acid, (iii) alarm substance + Cortland's, and (iv) alarm substance + acetic acid. Immediately after the injection, the animals were transferred to the observation tank, and their behavior was video recorded for $10 \mathrm{~min}$. Digitized video files were then analyzed, and four categories were scored: bottomdwelling (percentage of session time spent in the bottom third of the tank), erratic swimming (percentage of session time spent swimming in a "zig-zag," unpredictable pattern), freezing (percentage of session time spent immobile, with the exception of eye and gill movements), and tail-beating (the number of tail-beat movements that did not lead to propulsion in the water). Data were analyzed using one-way analysis of variance (ANOVA) for each behavioral category, followed by Dunnett's post hoc test when appropriate.

Experiment 2: Effects of confinement stress on nociceptive-like responses in zebrafish

Two groups of animals ( $n=20$ per group) were transferred daily to the observation apparatus $(10 \mathrm{~cm}$ length x $10 \mathrm{~cm}$ width x $20 \mathrm{~cm}$ height Plexiglas tank containing water from the home tank) and left there, individually, to explore the tank for $10 \mathrm{~min}$. Afterward, they were returned to their home tank. On the sixth day, 16 animals were transferred to the observation apparatus and displaced to a small side of the aquarium by means of an opaque partition, restricting the individual to $8 \%$ of the aquarium water volume for $30 \mathrm{~min}$ (adapted from Auperin, Baroiller, Ricordel, Fostler, \& Prunet, 1997). Stressor efficacy was confirmed by observing increases in ventilatory frequency (data not shown). A second group of animals $(n=16)$ was not subjected to confinement stress.
Afterward, the animals were removed from the tank and injected with either Cortland saline solution or Cortland's solution with $1 \%$ acetic acid, similar to Experiment 1. The final composition of the groups in Experiment 2 was the following: (i) no confinement + Cortland's, (ii) no confinement + acid, (iii) confinement + Cortland's, and (iv) confinement + acid. The same behavioral categories as in Experiment 1 were analyzed.

\section{Experiment 3: Effect of apparatus novelty on} nociceptive-like responses in zebrafish

For this experiment, one group of animals $(n=16)$ was transferred daily to the observation apparatus (10 cm length x $10 \mathrm{~cm}$ width x $20 \mathrm{~cm}$ height Plexiglas tank containing water from the home tank) and left there, individually, to explore the tank for $10 \mathrm{~min}$. Afterward, they were returned to their home tank. On the sixth day, this group, as well as a second group of animals that was not previously exposed to the apparatus, was injected with either Cortland saline solution or Cortland's solution with $1 \%$ acetic acid, similar to Experiment 1. The final composition of the groups in Experiment 3 was the following: ( $i$ ) habituation + Cortland's, (ii) habituation + acid, (iii) no habituation + Cortland's, and (iv) no habituation + acid. The same behavioral categories as in Experiment 1 were analyzed.

\section{Results}

Exposure to alarm substance induces hypoalgesia in zebrafish

The alarm substance increased bottom-dwelling $\left(F_{1,33}=25.87, p<.0001\right)$, erratic movements $\left(F_{1,33}=\right.$ $38.93, p=.0299)$, and freezing $\left(F_{1,33}=34.56, p<.0001\right)$ compared with non-exposed animals in the control situation (i.e., animals injected with Cortland's solution; Bonferroni post hoc test: $t \geq 2.698, p<.05$; Figure 1AC). The injection of acetic acid did not produce changes in bottom-dwelling or freezing in any of the conditions $\left(F_{1,33}<4.139, p>.05\right.$; Figure 1A, C), but it increased erratic swimming $\left(F_{1,33}=16.91, p=.002\right)$ and tail-beating $\left(F_{1,33}=25.87, p<.0001\right)$, a behavior that did not appear in the conditions without acid injection. Pre-exposure to the alarm substance, in contrast, reduced the levels of these measures to near control values (Bonferroni post hoc test: $t=7.511, p<.001$, for tail-beating; $t=6.282, p$ $<.001$, for erratic swimming; Figure 1B, D).

\section{Confinement stress induces hypoalgesia in zebrafish}

Confinement stress increased bottom-dwelling $\left(F_{1,36}=21.16, p<.0001\right)$ and freezing $\left(F_{1,36}=182.3\right.$, $p<.0001)$ compared with non-confined, Cortland'sinjected control animals (Bonferroni post hoc test: $t \geq$ 5.091, $p<.001$; Figure 2A, C). Freezing also increased in acid-injected animals after confinement (Bonferroni post hoc test: $t=4.351, p<.001)$. Confining the animals 


\section{Bottom-dwelling}

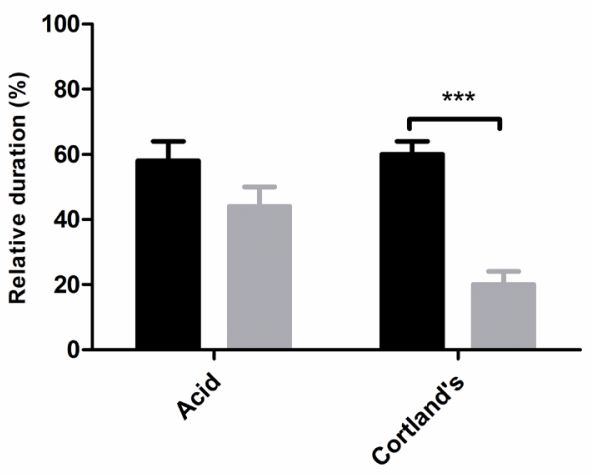

Freezing

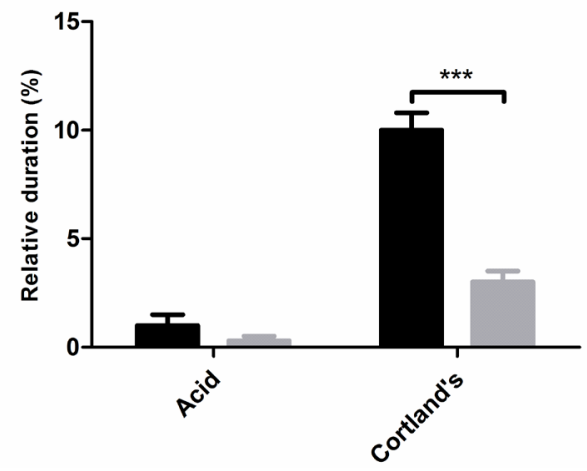

\section{Erratic movement}

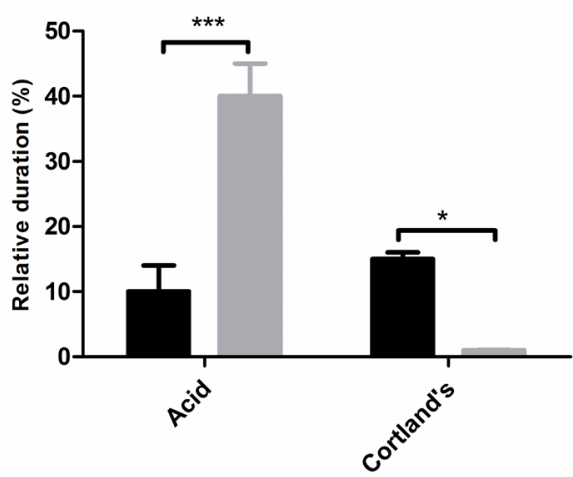

Tail-beating

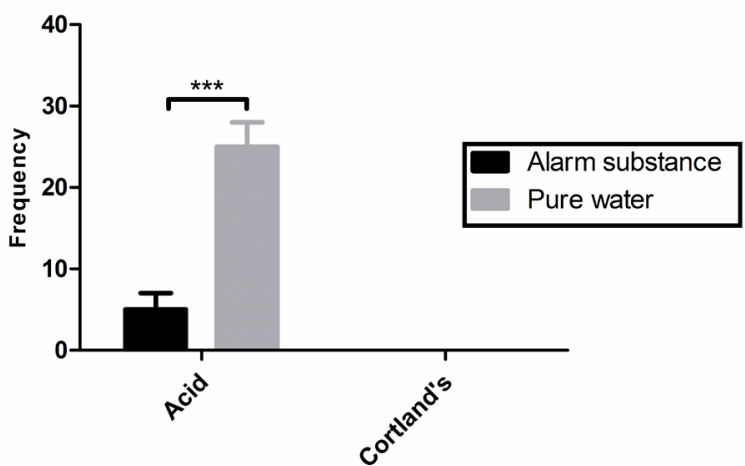

Figure 1. Effects of pre-exposure to the alarm substance (black bars) or pure water (gray bars) on (A) bottom-dwelling, (B) erratic swimming, (C) freezing, and (D) tail-beating in acetic acid- or Cortland solution-injected zebrafish. ${ }^{*} p<.05, * * * p<.001$.

\section{Bottom-dwelling}

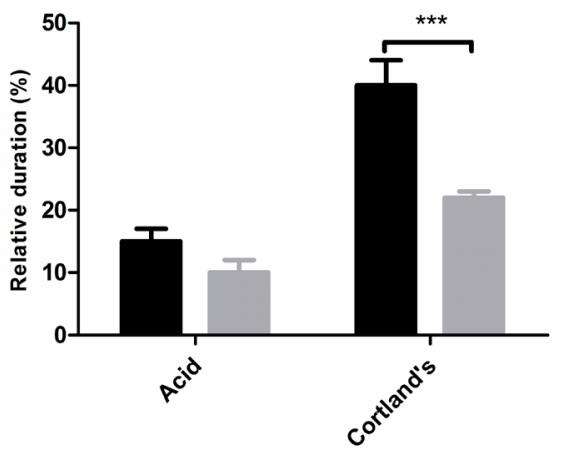

Freezing

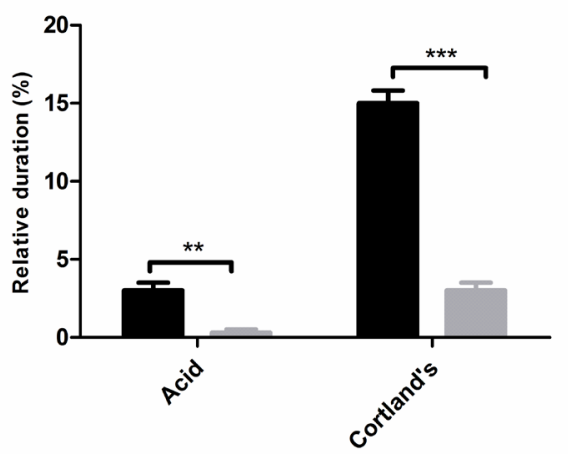

Erratic movement

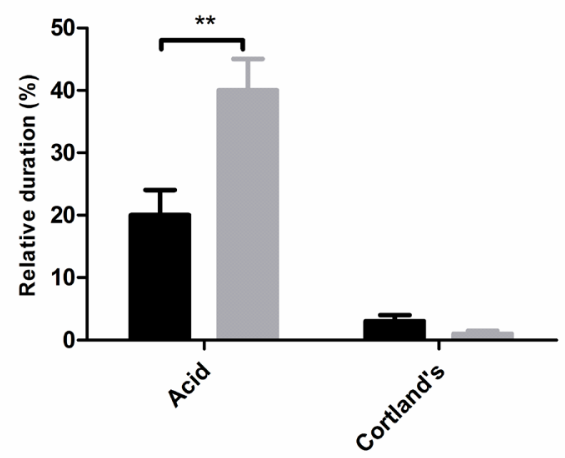

Tail-beating

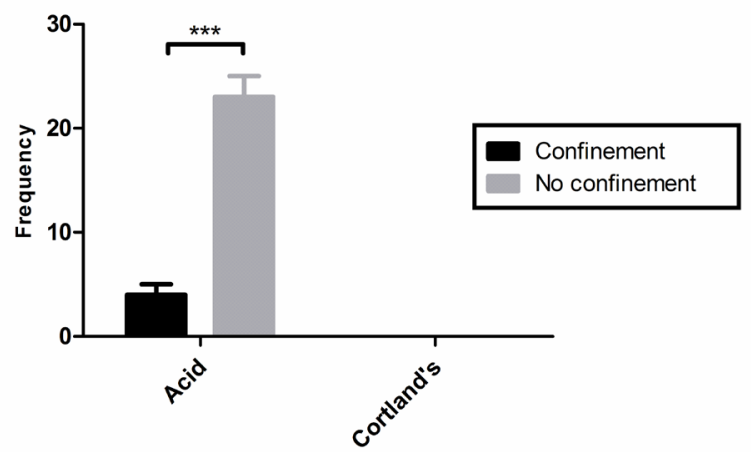

Figure 2. Effects of confinement stress (black bars) and no confinement (gray bars) on (A) bottom-dwelling, (B) erratic swimming, (C) freezing, and (D) tail-beating in acetic acid- or Cortland solution-injected zebrafish. ${ }^{* *} p<.01, * * * p<.001$. 
for $30 \mathrm{~min}$ prevented the increase in erratic swimming and tail-beating that was observed with injection of acetic acid in non-stressed animals (erratic swimming: $F_{1,36}=11.46, p=.0017$, Figure 2B; tail-beating: $F_{1,36}=$ $72.2, p<.0001$, Figure 2D). Again, tail beating did not appear in the conditions without acid injection.

\section{Bottom-dwelling}

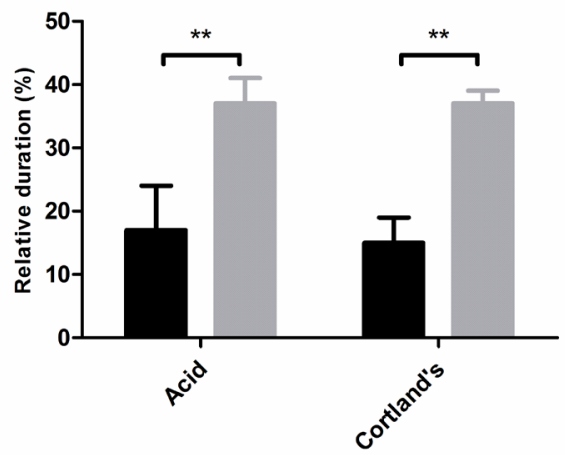

Freezing

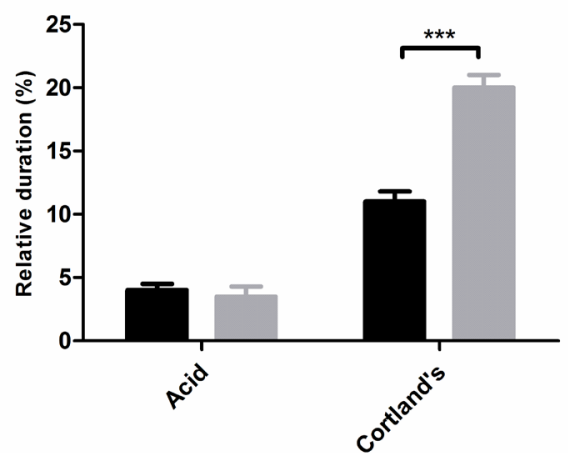

Environmental novelty induces hyperalgesia in zebrafish

Prior habituation to the test tank decreased bottom-dwelling $\left(F_{1,36}=20.75, p<.0001\right.$; Figure 3A) and freezing $\left(F_{1,36}=28.56, p<.0001\right.$; Figure $\left.3 \mathrm{C}\right)$ in Cortland's-injected animals and acid-injected animals (Bonferroni post hoc test: $t=3.068, p<.01$; Figure 3A).
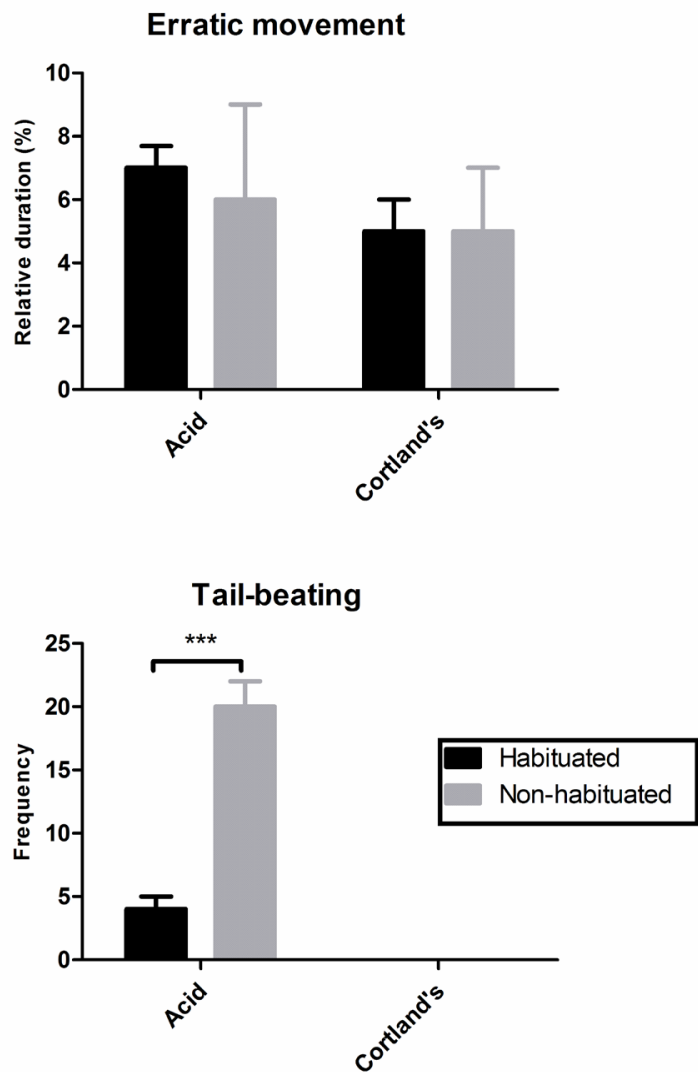

Figure 3. Effects of habituation (black bars) or no habituation (gray bars) on (A) bottom-dwelling, (B) erratic swimming, (C) freezing, and (D) tail-beating in acetic acid- or Cortland solution-injected zebrafish. $* * p<.01, * * * p<.001$.

Habituation decreased tail-beating behavior $\left(F_{1,36}=\right.$ 51.2, $p<.0001$; Figure 3D). No difference was observed in the other measures $\left(F_{1,36}<4.113, p>.05\right.$; Figure $3 \mathrm{~A}$ C). Again, tail beating did not appear in the conditions without acid injection.

\section{Discussion}

The present work reported the behavioral consequences of injecting a chemical irritant, acetic acid, in the tail of zebrafish and its modulation after exposure to different environmental stressors. Acetic acid injection selectively increased the amount of erratic swimming and produced a very specific display of tailbeating behavior, without affecting bottom-dwelling and freezing (i.e., two behavioral reactions to aversive stimulation observed in zebrafish in response to novelty or fear-eliciting stimuli; Gerlai, 2010; Maximino et al., 2010). Pre-exposure to the alarm substance increased freezing, bottom-dwelling, and erratic movement in animals that were not injected with acetic acid, consistent with the elicitation of fear (Gerlai, 2010; Maximino et al., 2010). In animals that were injected with acetic acid, pre-exposure to the alarm substance prevented the increase in erratic swimming and tailbeating, suggesting an antinociceptive effect of fear.

Confinement stress increased bottom-dwelling and freezing in Cortland's-injected animals, consistent with the behavioral responses to stress observed in other teleost fish (Øverli, Sorensen, \& Nilsson, 2006; Pottinger, \& Carrick, 2001; van Raaij, Pit, Balm, Steffens, \& van den Thillart, 1996; Verbeek, Iwamoto, $\&$ Murakami, 2008). These results confirm that the confinement protocol produced stress in zebrafish. Moreover, confinement stress prevented the increase in erratic swimming and tail-beating in acid-injected animals, suggesting that acute stress also produces an antinociceptive effect.

Habituation to the test tank decreased bottomdwelling and freezing, suggesting that the novelty of the environment is anxiogenic to zebrafish (Egan et al., 2009; Wong et al., 2010). Tail-beating frequency was 
diminished in habituated animals that were injected with acetic acid. This reduction in tail-beating by previous habituation suggests that novelty (and therefore anxiety) has pro-nociceptive effects in zebrafish.

These results suggest the existence of adaptive mechanisms in zebrafish that inhibit nociception in situations of threat and release it in situations of novelty or expectancy. These results are consistent with Walters' (1994) general adaptive model of injury-related behavior, in which proximate and distal threatening situations signal a high probability of injury, which elicits a fear state that inhibits pain. When the probability of injury is low, however, animals should display increased anxiety and increased pain. These results are not better explained by attentional models of pain (Arntz, Dreessen, \& de Jong, 1994; Janssen \& Arntz, 1996; Malow, 1981; McCaul \& Malott, 1984). These interpretations suggest (perhaps correctly) that fear draws attention away from nociceptive stimuli, but anxiety should also divert attention from pain processing. If novelty is "less salient" than noxious stimuli (as Sneddon et al., 2003b, proposed), however, then habituation to the test tank should not change the measures of nociceptive-like behavior. Therefore, the best explanation for the current data is that fear, stress, and anxiety, and not attentional biases, produced effects on analgesia.

The neural mechanisms of fear-induced analgesia are rather well-described. A network that includes the ventrolateral periaqueductal gray area, hippocampus, amygdala, and hypothalamus converges to rostroventral medullary (RVM) cells (mainly the medial nucleus raphe magnus), which in turn modulate spinal nociceptive processing (Gebhart, 1986; Hammond, 1986). Low-intensity electrical stimulation of these RVM cells decreases nociception and spinal nociceptive transmission in rats, whereas high-intensity stimulation increases both measures. A similar effect is observed with microinjection of low and high concentrations of glutamate or neurotensin in the RVM (Gebhart, 2004). This may be the neural substrate for the modulation of nociception by fear and anxiety observed elsewhere and in the present work.

Overall, this preliminary study provides good evidence of the descending modulation of nociception in zebrafish and opens new avenues for further investigations that relate these effects to their neural, genetic, and developmental underpinnings.

\section{Acknowledgments}

CM is a recipient of a CAPES studentship grant.

\section{References}

Alderman, S.L., \& Bernier, N.J. (2007). Localization of corticotropinreleasing factor, urotensin I, and CRF-binding protein gene expression in the brain of the zebrafish, Danio rerio. Journal of Comparative Neurology, 502, 783-793.
Amit, Z., \& Galina, Z.H. (1986). Stress-induced analgesia: adaptive pain suppression. Physiological Reviews, 66, 1091-1120.

Ampatzis, K., \& Dermon, C.R. (2010). Regional distribution and cellular localization of $b_{2}$-adrenoceptors in the adult zebrafish brain (Danio rerio). Journal of Comparative Neurology, 518, 1418-1441.

Ampatzis, K., Kentouri, M., \& Dermon, C.R. (2008). Neuronal and glial localization of $\mathrm{a}_{2 \mathrm{~A}}$-adrenoceptors in the adult zebrafish (Danio rerio) brain. Journal of Comparative Neurology, 508, 72-93.

Andersen, M.L., D’Almeida, V., Ko, G.M., Kawakami, R., Martins, P.J.F., Magalhães, L.E. (2008). Princípios éticos e práticos do uso de animais de experimentação. São Paulo: Universidade Federal Paulista / SBCAL.

Arntz, A., Dreessen, L., \& de Jong, P. (1994). The influence of anxiety on pain: attentional and attributional mediators. Pain, 56, 307-314.

ASAB/ABS (2006). Guidelines for the treatment of animals in behavioural research and teaching. Animal Behavior, 71, 245-253.

Auperin, B., Baroiller, J.F., Ricordel, M.J., Fostier, A., \& Prunet, P. (1997). Effect of confinement stress on circulating levels of growth hormone and two prolactins in freshwater-adapted tilapia (Oreochromis niloticus). General and Comparative Endocrinology, 108, 35-44.

Barcellos, L.J.G., Ritter, F., Kreutz, L.C., Quevedo, R.M., Silva, L.B., Bedin, A.C., Finco, J., \& Cericato, L. (2007). Whole-body cortisol increases after direct and visual contact with a predator in zebrafish, Danio rerio. Aquaculture, 272, 774-778.

Barrallo, A., Gonzalez-Sarmiento, R., Alvar, F., \& Rodríguez, R.E. (2000). ZFOR2, a new opioid receptor-like gene from the teleost zebrafish (Danio rerio). Molecular Brain Research, 84, 1-6.

Becker, T., Wullimann, M.F., Becker, C.G., Bernhardt, R.R., \& Schachner, M. (1997). Axonal regrowth after spinal cord transection in adult zebrafish. Journal of Comparative Neurology, 377, 577-595.

Blanchard, D.C., \& Blanchard, R.J. (2008). Defensive behaviors, fear, and anxiety. In R.J. Blanchard, D.C. Blanchard, G. Griebel, \& D. Nutt (Eds.), Handbook of anxiety and fear (vol. 17, pp. 63-79). Amsterdam: Academic Press.

Bodnar, R.J., Kelly, D.D., Spiaggia, A., Ehrenberg, C., \& Glusman, M. (1978). Dose-dependent reductions by naloxone of analgesia induced by cold-water stress. Pharmacology Biochemistry and Behavior, 8, 667-672.

Bodnar, R.J., Glusman, M., Brutus, M., Spiaggia, A., \& Kelly, D.D. (1979). Analgesia induced by cold-water stress: attenuation following hypophysectomy. Physiology and Behavior, 23, 53-62.

Bodnar, R.J., Merrigan, K.P., \& Sperber, E. (1983). Potentiation of cold-water swim analgesia and hypothermia by clonidine. Pharmacology Biochemistry and Behavior, 19, 447-451.

Bolles, R.C., \& Fanselow, M.S. (1980). A perceptual-defensiverecuperative model of fear and pain. Behavioral and Brain Sciences, 3, 291-323.

Butler, R.K., \& Finn, D.P. (2009). Stress-induced analgesia. Progress in Neurobiology, 88, 184-202.

Chandrasekar, G., Lauter, G., \& Hauptmann, G. (2007). Distribution of corticotropin-releasing hormone in the developing zebrafish brain. Journal of Comparative Neurology, 505, 337-351.

Costa, A., Smeraldi, A., Tassorelli, C., Greco, R., \& Nappi, G. (2005). Effects of acute and chronic restraint stress on nitroglycerininduced hyperalgesia in rats. Neuroscience Letters, 383, 7-11.

Dunlop, R., \& Laming, P. (2005). Mechanoreceptive and nociceptive responses in the central nervous system of goldfish (Carassius auratus) and trout (Oncorhynchus mykiss). Journal of Pain, 6, 561-568.

Egan, R.J., Bergner, C.L., Hart, P.C., Cachat, J.M., Canavello, P.R., Elegante, M.F.,...Kalueff, A.V. (2009). Understanding behavioral and physiological phenotypes of stress and anxiety in zebrafish. Behavioural Brain Research, 205, 38-44.

Gebhart, G.F. (1986). Modulatory effects of descending systems on spinal dorsal horn neurons. In T. Yaksh \& F.W.L. Kerr (Eds.), Spinal afferent processing (pp. 391-416). New York: Plenum Press.

Gebhart, G.F. (2004). Descending modulation of pain. Neuroscience and Biobehavioral Reviews, 27, 729-737.

Gerlai, R. (2010). Zebrafish antipredatory responses: a future for translational research? Behavioural Brain Research, 207, 223-231.

González-Nuñez, V., Gonzalez-Sarmiento, R., \& Rodríguez, R.E. (2003a). Characterization of zebrafish proenkephalin reveals novel opioid sequences. Molecular Brain Research, 114, 31-39.

González-Nuñez, V., Gonzalez-Sarmiento, R., \& Rodríguez, R.E. (2003b). Cloning and characterization of a full-length pronociceptin 
in zebrafish: evidence of the existence of two different nociceptin sequences in the same precursor. Acta Biochimica et Biophysica, $1629,114-118$.

González-Nuñez, V., Gonzalez-Sarmiento, R., \& Rodríguez, R.E. $(2003 c)$. Identification of two proopiomelanocortin genes in zebrafish (Danio rerio). Molecular Brain Research, 120, 1-8.

González-Nuñez, V., Barallo, A., Traynor, J.R., \& Rodríguez, R.E. (2006). Characterization of opioid-binding sites in zebrafish brain. Journal of Pharmacology and Experimental Therapeutics, 316, 900-904.

González-Nuñez, V., \& Rodriguez, R.E. (2009). The zebrafish: a model to study the endogenous mechanisms of pain. ILAR Journal, 50, 373-386.

Hammond, D.L. (1986). Control systems for nociceptive afferent processing: the descending inhibitory pathways. In T. Yaksh \& F.W.L. Kerr (Eds.), Spinal afferent processing (pp. 391-416). New York: Plenum Press.

Janssen, S.A., \& Arntz, A. (1996). Anxiety and pain: attentional and endorphinergic influences. Pain, 66, 145-150.

Kim, Y.J., Nam, R.H., Yoo, Y.M., \& Lee, C.J. (2004). Identification and functional evidence of GABAergic neurons in parts of the brain of adult zebrafish (Danio rerio). Neuroscience Letters, 355, $29-32$.

Lam, C.S., Rastegar, S., \& Strähle, U. (2006). Distribution of cannabinoid receptor 1 in the CNS of zebrafish. Neuroscience, 138 , $83-95$.

Lillesaar, C., Stigloher, C., Tannhäuser, B., Wullimann, M.F., \& BallyCuif, L. (2009). Axonal projections originating from the raphe serotonergic neurons in the developing and adult zebrafish, Danio rerio, using transgenics to visualize raphe-specific pet 1 expression. Journal of Comparative Neurology, 512, 158-182.

Liu, R.P.C. (1986). Spinal neuronal collaterals to the intralaminar thalamic nuclei and periaqueductal gray. Brain Research, 365, 145-150.

Malow, R.M. (1981). The effects of induced anxiety on pain perception: a signal detection analysis. Pain, 11, 397-405.

Mathur, P., \& Guo, S. (2010). Use of zebrafish as a model to understand mechanisms of addiction and complex neurobehavioral phenotypes. Neurobiology of Disease, 40, 66-72.

Maximino, C., de Brito, T.M., da Silva Batista, A.W., Herculano, A.M., Morato, S., \& Gouveia, A., Jr. (2010). Measuring anxiety in zebrafish: a critical review. Behavioural Brain Research, 214, $157-171$.

McCaul, K., \& Malott, J. (1984). Distraction and coping with pain. Psychological Bulletin, 95, 516-533.

McNaughton, N., \& Corr, P.J. (2004). A two-dimensional neuropsychology of defense: fear/anxiety and defensive distance. Neuroscience and Biobehavioral Reviews, 28, 285-305.

Nordgreen, J., Garner, J.P., Janczak, A.M., Ranheim, B., Muir, W.M., \& Horsberg, T.E. (2009). Thermonociception in fish: effects of two different doses of morphine on thermal threshold and posttest behaviour in goldfish (Carassius auratus). Applied Animal Behaviour Science, 119, 101-107.

Nordgreen, J., Horsberg, T.E., Ranheim, B., \& Chen, A.C.N. (2007). Somatosensory evoked potentials in the telencephalon of Atlantic salmon (Salmo salar) following galvanic stimulation of the tail. Journal of Comparative Physiology: A. Sensory, Neural, and Behavioral Physiology, 193, 1235-1242.

Norton, W., \& Bally-Cuif, L. (2010). Adult zebrafish as a model organism for behavioural genetics. BMC Neuroscience, 11, 90 .

Øverli, Ø., Sorensen, C., \& Nilsson, G.E. (2006). Behavioral indicators of stress-coping style in rainbow trout: do males and females react differently to novelty? Physiology and Behavior, 87, 506-512.

Perry, S.F., Davie, P.S., Daxboeck, C., Ellis, A.G., \& Smith, D.G. (1984). Perfusion methods for the study of gill physiology. In W.S. Hoar \& D.J. Randall (Eds.), Gills: Part B. Ion and water transfer (series title: Fish physiology, vol. 10). Orlando: Academic Press.
Pfeiffer, W. (1977). The distribution of fright reaction and alarm substance cells in fishes. Copeia, 4, 653-665.

Pottinger, T.G., \& Carrick, T.R. (2001). Stress responsiveness affects dominance-subordinate relationships in rainbow trout. Hormones and Behavior, 40, 419-427.

Powell, S.B., Geyer, M.A., Gallagher, D., \& Paulus, M.P. (2004). The balance between approach and avoidance behaviors in a novel object exploration paradigm in mice. Behavioural Brain Research, 152, 341-349.

Prober, D.A., Zimmerman, S., Myers, B.R., McDermott, B.M., Jr., Kim, S.H., Caron, S.,...Schier, A.F. (2008). Zebrafish TRPA1 channels are required for chemosensation but not for thermosensation or mechanosensory hair cell function. Journal of Neuroscience, 28, 10102-10110.

Puglisi-Allegra, S., \& Oliverio, A. (1983). Social isolation: effects on pain threshold and stress-induced analgesia. Pharmacology Biochemistry and Behavior, 19, 679-681.

Reilly, S.C., Quinn, J.P., Cossins, A.R., \& Sneddon, L.U. (2008a). Behavioral analysis of a nociceptive event in fish: comparisons between three species demonstrate specific responses. Applied Animal Behaviour Science, 114, 248-259.

Reilly, S.C., Quinn, J.P., Cossins, A.R., \& Sneddon, L.U. (2008b). Novel candidate genes identified in the brain during nociception in common carp (Cyprinus carpio) and rainbow trout (Oncorhynchus mykiss). Neuroscience Letters, 437, 135-138.

Rhudy, J.L., \& Meagher, M.W. (2000). Fear and anxiety: divergent effects on human pain thresholds. Pain, 84, 65-75.

Rodríguez, R.E., Barrallo, A., García-Malvar, F., McFayden, I.J., Gonzalez-Sarmiento, R., \& Traynor, J.R. (2000). Characterization of ZFOR1, a putative delta-opioid receptor from the teleost zebrafish (Danio rerio). Neuroscience Letters, 288, 207-210.

Sneddon, L.U. (2003a). The evidence for pain in fish: the use of morphine as an analgesic. Applied Animal Behaviour Science, 83, 153-162.

Sneddon, L.U. (2003b). Trigeminal sensory innervation of the head of a teleost fish with particular reference to nociception. Brain Research, 972, 44-52.

Sneddon, L.U., \& Gentle, M.J. (2002). Receptor types on the head of the rainbow trout: are nociceptors present? Comparative Biochemistry and Physiology: A. Comparative Physiology 32, S42.

Sneddon, L.U., Braithwaite, V.A., \& Gentle, M.J. (2003a). Do fishes have nociceptors? Evidence for the evolution of a vertebrate sensory system. Proceedings of the Royal Society B: Biological Sciences, 270, 1115-1121.

Sneddon, L.U., Braithwaite, V.A., \& Gentle, M.J. (2003b). Novel object test: examining nociception and fear in the rainbow trout. Journal of Pain, 4, 431-440.

van Raaij, M.T.M., Pit, D.S.S., Balm, P.H.M., Steffens, A.B., \& van den Thillart, G.E.E.J.M. (1996). Behavioral strategy and the physiological stress response in rainbow trout exposed to severe hypoxia. Hormones and Behavior, 30, 85-92.

Verbeek, P., Iwamoto, T., \& Murakami, N. (2008). Variable stressresponsiveness in wild type and domesticated fighting fish. Physiology and Behavior, 93, 83-88.

von Frisch, K. (1938). Zur psychologie des fisch-schwarmes. Naturwissenschaften, 26, 601-606.

von Frisch, K. (1941). Über einen Schreckstoff der Fischk- haut und seine biologische Bedeutung. Z Vergl Physiol, 29, 46-145.

Waldman, B. (1982). Quantitative and developmental analyses of alarm reaction in the zebra danio, Brachydanio rerio. Copeia, 1, 1-9.

Walters, E.T. (1994). Injury related behavior and neuronal plasticity: an evolutionary perspective on sensitization, hyperalgesia, and analgesia. International Review of Neurobiology, 36, 325-427.

Wong, K., Elegante, M., Bartels, B., Elkhayat, S., Tien, D., Roy, S.,... Kalueff, A.V. (2010). Analyzing habituation responses to novelty in zebrafish (Danio rerio). Behavioural Brain Research, 208, 450-457. 